\title{
Arqueologia Jê no Estado de São Paulo
}

Marisa Coutinho Afonso*

AFONSO, M.C. Arqueologia Jê no Estado de São Paulo. R. Museu Arq. Etn., 27: 30-43, 2016.

Resumo: Este artigo apresenta uma síntese da ocupação Jê no Estado de São Paulo e discute seus contextos arqueológicos, geográficos e cronológicos. Trata dos sítios associados a grupos Jê e filiados às tradições Itararé-Taquara, Aratu-Sapucaí e Uru.

Palavras-chave: Arqueologia Jê; Grupos ceramistas; Tradição Itararé; Tradição Aratu; São Paulo; Fronteiras culturais.

\section{Introdução}

Tnestigações sobre fronteiras dos grupos

ceramistas no Estado de São Paulo são realizadas há vários anos para se compreender melhor a ocupação dos grupos Tupi e Jê, com base na análise do conhecimento produzido por pesquisas arqueológicas acadêmicas, antigas e atuais, e projetos de arqueologia preventiva. Um levantamento dos sítios filiados às tradições Itararé, Aratu e Uru mostra que as ocupações Jê se distribuem por todo o território paulista, de norte a sul, do litoral ao interior.

O entendimento destas ocupações é fundamental para se compreender as rotas de dispersão dos grupos Jê meridionais e dos grupos Jê do Planalto Central; portanto a pesquisa arqueológica do território paulista pode contribuir para o melhor entendimento do contexto espacial e temporal dos grupos ceramistas de várias regiões brasileiras (sudeste, sul e centro-oeste).

Neste artigo pretendo apresentar uma síntese da ocupação Jê no Estado de São

${ }^{*}$ Museu de Arqueologia e Etnologia, Universidade de São Paulo. Coordenadora do Laboratório de Arqueologia da Paisagem e Geoarqueologia (LAPGEO-MAE/USP). <marisa. afonso@usp.br>
Paulo e discutir seus contextos arqueológicos, geográficos e cronológicos. Serão abordados os sítios associados a grupos Jê, filiados às tradições Aratu-Sapucaí, Uru e Itararé-Taquara ${ }^{1}$.

\section{Grupos ceramistas em São Paulo}

Afonso (2005) organizou uma síntese do conhecimento arqueológico do Estado de São Paulo englobando também os sítios cerâmicos. A ocupação dos grupos ceramistas foi objeto de várias publicações posteriores (Afonso et al. 2009; Afonso 2008/2009, 2014; Perez et al. 2015) quando foram discutidos os sítios Tupi (tradição Tupiguarani) que apresentam uma variabilidade na cerâmica, apontando uma diversidade regional, e os sítios associados a grupos Jê, filiados às tradições Itararé, Aratu e Uru.

A distribuição dos sítios cerâmicos no Estado de São Paulo apresenta uma complexidade que reflete contextos de interação cultural. Grupos vindos de outras regiões trouxeram características próprias identificadas em vários sítios localizados durante a realização de projetos recentes ou em desenvolvimento, acadêmicos e de arqueologia preventiva.

1 Tradição Itararé-Taquara, tal como definido por Araujo (2007). 
Em São Paulo, os sítios cerâmicos começaram a ser pesquisados sistematicamente na Bacia do rio Paranapanema por Luciana Pallestrini (Museu Paulista, Universidade de São Paulo) na década de 1960 no Projeto Paranapanema, em desenvolvimento até hoje com coordenação de José Luiz de Morais (Pallestrini 1968/1969, Morais 2011a: 39-40). Desde o início, este projeto empregou métodos de campo modernos como a adaptação das técnicas de escavação de André Leroi-Gourhan, que Pallestrini (1983) denominou "ataque em superfícies amplas". Apresentou um enfoque interdisciplinar, como na área da arqueometria, já que foi a primeira vez que a técnica de datação de cerâmica por termoluminescência foi realizada em São Paulo. Também foi pioneiro na análise espacial e representação cartográfica com a produção das primeiras plantas de aldeias ceramistas Guarani do Estado de São Paulo. Silvia Maranca (Museu Paulista, USP) desenvolveu a partir da década de 1960 várias pesquisas com sítios cerâmicos no interior de São Paulo, como parte do Programa Nacional de Pesquisas Arqueológicas - Pronapa (Maranca 1968/1969, 1969). Tom Miller Júnior (Miller Jr. 1972) tratou dos sítios cerâmicos da região de Rio Claro, na parte central do estado de São Paulo. A ênfase era maior nos sítios da tradição Tupiguarani que foram localizados em diversas áreas do Estado.

Robrahn-González (2000) agrupou as indústrias dos cerca de 200 sítios cerâmicos conhecidos em São Paulo até o final da década de 1990 em três grandes unidades classificatórias: a tradição Tupiguarani, mais antiga, com vestígios que se distribuem por todo o Estado de São Paulo; a tradição Itararé, com sítios localizados na porção sul e a tradição Aratu-Sapucaí com sítios na região norte.

Zanettini Arqueologia (2010: 40) apontou 50 sítios Jê cadastrados no Estado de São Paulo; além dos grupos Tupi, mencionados nos documentos históricos de São Paulo colonial, havia os grupos falantes de línguas Jê (os "tapuias", como eram chamados pelos Tupi e pelos colonizadores portugueses) associados às tradições Aratu e Uru. Para Zanettini Arqueologia (2010: 40) a descoberta de sítios Aratu e Uru em São Paulo é importante e reforça a ideia de que o território paulista foi um verdadeiro mosaico cultural.
Além de sítios da tradição Tupiguarani, espalhados por todo o estado, é possível identificar a tradição Itararé/Taquara, com sítios localizados na porção sul e em Ilhabela (litoral norte); a tradição Aratu-Sapucaí com sítios na região norte-nordeste (bacias do rio Grande e do rio Paraíba do Sul) e a tradição Uru no norte de SP (bacia do rio Grande).

\section{Sítios filiados à tradição Itararé-Taquara em São} Paulo

Miller Jr. (1972) foi o primeiro arqueólogo a identificar sítios filiados à tradição Itararé em São Paulo, na região de Rio Claro e Charqueada (bacia do rio Tietê) e também na região noroeste (Parapuã e Lucélia). No final desta mesma década, Prous (1979) identificou casas subterrâneas na região de Itapeva (bacia do rio Paranapanema), no sul de São Paulo.

Robrahn (1989) localizou muitos sítios filiados à tradição Itararé, no sul do Estado de São Paulo, no vale médio do rio Ribeira de Iguape e dividiu os sítios cerâmicos em três categorias: a céu aberto (forma entre arredondada e elíptica, $550 \mathrm{~m}^{2}$ de dimensão e $20 \mathrm{~cm}$ de espessura), grutas (6 a $130 \mathrm{~m}^{2}$ ) e cemitérios (montículos). Nos vales médio e alto do rio Ribeira de Iguape, foram identificados sítios cerâmicos constituídos por estruturas de pequenas dimensões, implantadas em várias formas de relevo como fundo de vale, baixa, média e alta vertentes, cristas dos divisores de água (Robrahn-González 1989: 295). Segundo a autora, a cerâmica destes sítios apresentou vasilhames predominantemente pequenos (46,8\% com capacidade de até 1 litro), médios (38,7\% de 1,1 e 4 litros) e grandes (14,5\% acima de 4,1 litros, alcançando um máximo de 58 litros).

Devido às pesquisas de Robrahn (1989) durante algum tempo pensou-se que os sítios de tradição Itararé em São Paulo teriam sempre pequenas dimensões. No entanto, esta ideia foi contraposta à descoberta de sítios desta tradição localizados em outras regiões como no caso do sítio Areia Branca 5 em Itapeva (Araujo 2016) com dimensões maiores.

Souza e Merencio (2013), analisando os sítios Jê no Estado do Paraná, notaram que 
a ocupação Jê meridional é caracterizada, na maior parte das regiões, por sítios a céu aberto. Os autores comentaram o modelo de sistema de assentamento apresentado por Robrahn (1989: 126-132) para o vale do Ribeira de Iguape em São Paulo, com a classificação dos sítios de acordo com a densidade do material, com os sítios densos e médios interpretados como sítios de habitação e os de baixa densidade como sítios "satélite" ou de áreas de atividades específicas.

Araujo (2007: 20) discutiu a tradição Itararé-Taquara no estado de São Paulo apontando o Alto Paranapanema como o local com maior número de ocorrências. Além de citar os trabalhos de Prous (1979) e Araujo (1995, 2001) sobre casas subterrâneas e Miller Jr. (1972) nas regiões central e noroeste, apresentou várias evidências encontradas nos levantamentos arqueológicos realizados ao longo da margem direita (paulista) do Médio e Baixo Paranapanema e relacionadas à tradição Itararé-Taquara, como virotes, almofariz de pedra e socador de pedra cônico, e à tradição Aratu, como lâminas polidas semilunares. Também identificou no sítio Alves, escavado por Pallestrini (1974), sugestões de contato entre Kaingang e populações de filiação Guarani no Médio Paranapanema uma vez que duas urnas Tupiguarani continham vasilhames menores parecidos em forma e tecnologia aos encontrados nos sítios da tradição Itararé (Araujo 2007: 21).

$\mathrm{Na}$ bacia do rio Paranapanema (SP), Morais (1999/2000: 111) observou que a tradição Itararé apresentou-se de duas maneiras: compondo sítios próprios da tradição ou pela presença de materiais Kaingang em sítios de tradição Guarani. Este último caso ocorre principalmente no trecho médio-inferior da bacia, comprovando contatos entre os Guarani e Kaingang.

Araujo (2007: 21) no levantamento arqueológico na bacia do Alto Taquari, afluente do Paranapanema, na cidade de Itapeva, a $60 \mathrm{~km}$ da divisa com o Paraná e apenas $40 \mathrm{~km}$ serra acima dos sítios do Médio Ribeira, identificou 39 sítios arqueológicos relacionados à Tradição Itararé-Taquara incluindo sítios cerâmicos a céu aberto, em abrigo, montículos e casas subterrâneas. Para o autor, alguns sítios Itararé-Taquara foram localizados em locais surpreendentes pela ausência de relatos históricos diretos, como o sítio Jaraguá 1 (vale do rio Tietê) e o sítio Topo de Guararema (vale do rio Paraíba do Sul) que representam uma evidência da forte presença Jê do Sul nas regiões mais setentrionais da Serra do Mar (Araujo 2007: 22). Robrahn-González (2005) apresentou o sítio Jaraguá 1, localizado na cidade de São Paulo, próximo ao Pico do Jaraguá e datado em 660 anos BP (1.290 dC); associou-o aos grupos pertencentes ao tronco linguístico Macro-Gê e observou que apenas 200 anos depois desta data os colonizadores portugueses indicavam uma presença maciça de grupos Tupiguarani nos campos de Piratininga.

No alto Paranapanema, em Itapeva, foram localizados alguns sítios de tradição Itararé (Kaingang) durante o levantamento arqueológico na área de impacto do gasoduto Bolívia - Brasil (DeBlasis 2000). O sítio Areia Branca 6, localizado em Itapeva, foi identificado como cemitério pela presença de montículos de terra, relatados em fontes etnográficas como cemitérios Kaingang. O sítio, datado de $1430 \pm 60$ anos BP, foi objeto de estudo do solo e sedimentos por Amenomori (1999), principalmente para análise do fosfato. Amenomori (1999: 152) constatou que em certas áreas do montículo houve concentração no teor de fosfato, possibilitando interpretar a existência de um sepultamento que não se preservou.

Durante um projeto realizado pela Scientia Arqueologia, foi identificado o sítio Topo do Guararema (rio Paraíba do Sul) filiado à tradição Itararé. Este sítio encontra-se implantado em topo de morro, a $100 \mathrm{~m}$ da margem esquerda do rio Paraíba do Sul e a cerca de 3 $\mathrm{km}$ da sede do Município de Guararema, SP (Caldarelli 2015: 15). Segundo a autora, análises preliminares do material coletado durante a prospecção apontaram para vasilhas de contorno simples, não decoradas, com presença de antiplástico exclusivamente mineral; a área do sítio era de $5.700 \mathrm{~m}^{2}$, em posição privilegiada para visão dos arredores. Caldarelli (2015: 17) apontou que as análises do material arqueológico indicaram uma cerâmica assemelhada à produzida por populações Jê, atribuída à tradição Itararé: "manufatura por acordelamento; 
antiplástico predominantemente mineral, mas com presença de cariapé; queima totalmente redutora na maioria dos casos, indicando a utilização de fornos fechados; espessura das vasilhas pequena e pouco variada; lábios em sua maioria apontados, em bordas extrovertidas e reforçadas externamente; brunidura como tratamento de superfície preferencial, seguida de alisamento fino, em ambas as faces; bases geralmente planas, seguidas por bases convexas”. As datações obtidas indicam uma ocupação do sítio por um intervalo de cerca de 400 anos, entre 920 e 1.340 AD (Caldarelli 2015: 18-19). Caldarelli (2015) levantou algumas questões como a associação da cultura material do sítio Topo do Guararema à Tradição Itararé; ou a associação da tradição Itararé aos Kaingang, com uma ocupação indígena também Jê, mas relacionada à outra etnia ou se o Topo do Guararema seria um sítio dos Guaianás.

Faccio e Barrocá (2014) apontaram o sítio Kandiri (município de Pacaembu, bacia do rio do Peixe) como filiado à tradição Itararé, com a presença de cerâmica lisa e um fragmento de lâmina de machado semilunar. Segundo os autores, sítios da tradição Itararé são pouco conhecidos na região noroeste do Estado de São Paulo, mas há relatos etnohistóricos evidenciando a presença de índios Kaingang (do tronco linguístico Jê, associado a Tradição Itararé) nessa região.

Cali (2005: 91) desenvolveu um projeto de pesquisa em Ilhabela (litoral norte de São Paulo em 2000 e identificou sítios cerâmicos com a presença de potes de pequenas dimensões, paredes finas e quase sem decoração e filiou-os à tradição Itararé (sítios Viana e Barra Velha 3). Estes sítios representaram uma dupla novidade: assentamento da tradição Itararé em ilha e bem ao norte de São Paulo.

\section{As casas subterrâneas}

Com relação à distribuição geográfica, as casas subterrâneas ocorrem nos Estados do Rio Grande do Sul, Santa Catarina e Paraná e em menor frequência nos Estados de Minas Gerais e São Paulo (Milder 2005).

Em São Paulo, as casas subterrâneas foram reconhecidas pela primeira vez por Prous
(1979) que registrou a ocorrência de 4 sítios com 8 casas subterrâneas no bairro Itambé, Município de Itararé (atual Município de Bom Sucesso de Itararé), no sul do Estado. Foram localizados fragmentos cerâmicos finos, sem decoração e líticos polidos.

Araujo $(1995,2001)$ pesquisou a bacia do Alto Taquari (Municípios de Itapeva, Ribeirão Branco, Nova Campina e Bom Sucesso de Itararé) e localizou 4 casas subterrâneas, sendo duas (PR2 e FRC) com fragmentos de líticos lascados e outras duas (CSU, CS2) com fragmentos cerâmicos.

No Município de Itapeva, durante os levantamentos arqueológicos do Gasoduto Brasil-Bolívia (GASBOL), foram localizadas 4 casas subterrâneas chamadas de Apiaí-Mirim 1 a 4, mas sem a localização de vestígios arqueológicos na superfície (DeBlasis 2000).

Kamase $(2004,2005)$ voltou à região e partiu do levantamento de Araujo e do interesse em diferenciar as feições naturais, doliniformes (fig. 1), das arqueológicas (fig. 2). Encontrou uma feição doliniforme com abundância de material arqueológico no Município de Bom Sucesso de Itararé; esta feição já havia sido localizada por

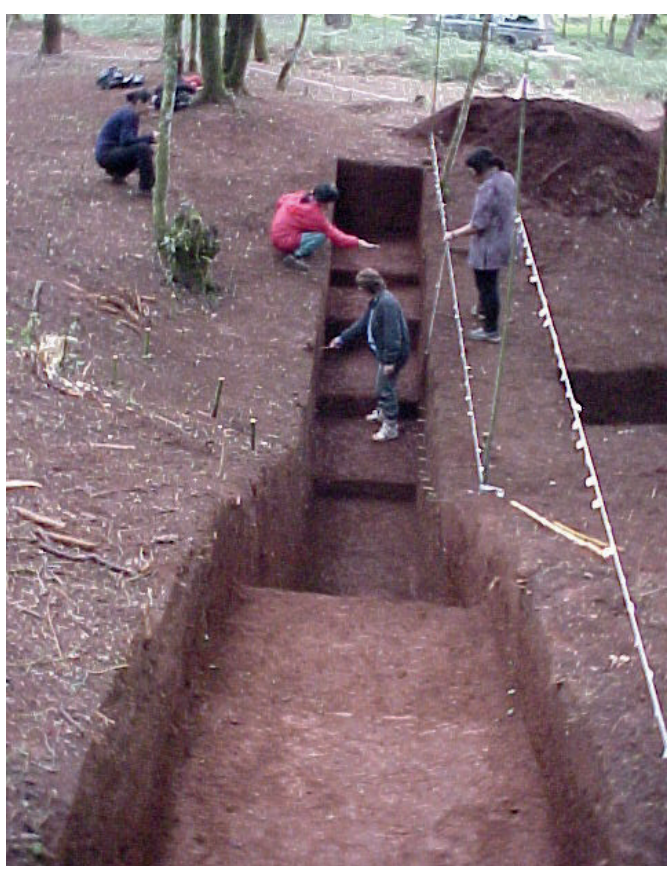

Fig. 1. Feição doliniforme (FD 24), Itapeva (SP). Pesquisa de Kamase (2004, 2005). Foto: Luciane Kamase. 


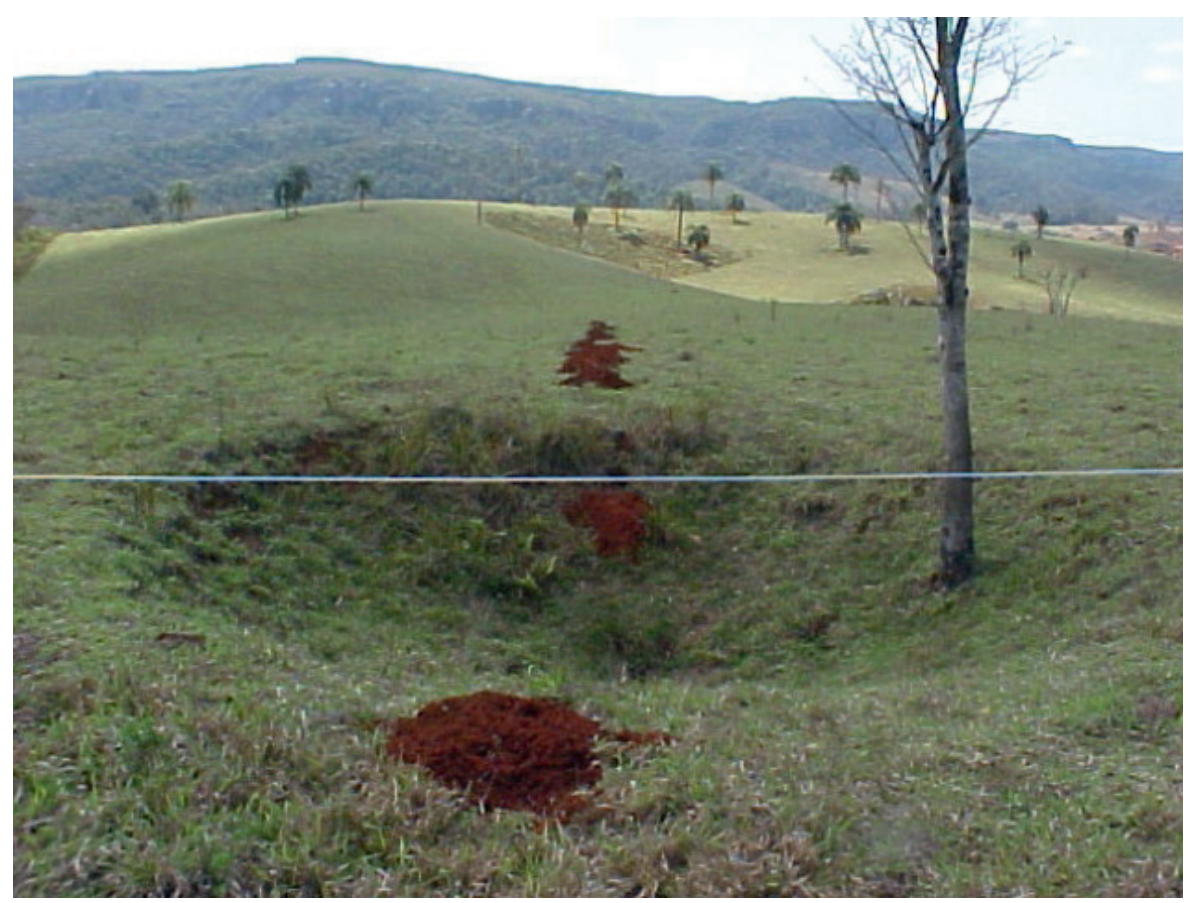

Fig. 2. Casa subterrânea localizada em Itapeva (SP) com cerâmica. Pesquisa de Kamase (2004, 2005). Foto: Luciane Kamase.

Araujo (1995) e situa-se próximo das casas subterrâneas localizadas por Prous (1979). Ocorreram fragmentos cerâmicos sem decoração também em profundidade nas tradagens e sondagem realizadas (fig. 3). Kamase (2005: 51) organizou uma tabela para o alto Taquari com 12 datações para 7 sítios filiados à tradição Itararé-Taquara inclusive a casa subterrânea que escavou. São os sítios Areia Branca 5 e Areia Branca 6 (DeBlasis 2000); Arlindo Cruz, Gasbol 8, Müzel e Quatis (Araujo 2001) e Casa subterrânea CSU120 (Kamase 2005). Para este último sítio, Kamase (2005: 51) obteve as seguintes datas por termoluminescência: $1200 \pm 120$ e $1530 \pm 150$ e indicou que as idades mais recentes são em torno de 750 anos e as mais recuadas $1700 \mathrm{BP}$.

Afonso e Morais (2005) apontaram que, durante os levantamentos arqueológicos para a duplicação da Rodovia Régis Bittencourt, o sítio Barra do Turvo foi localizado no Município de mesmo nome, no sul do Estado de São Paulo, quase no limite com o Estado do Paraná. Trata-se da única casa subterrânea localizada até o momento no vale do rio Ribeira de Iguape e

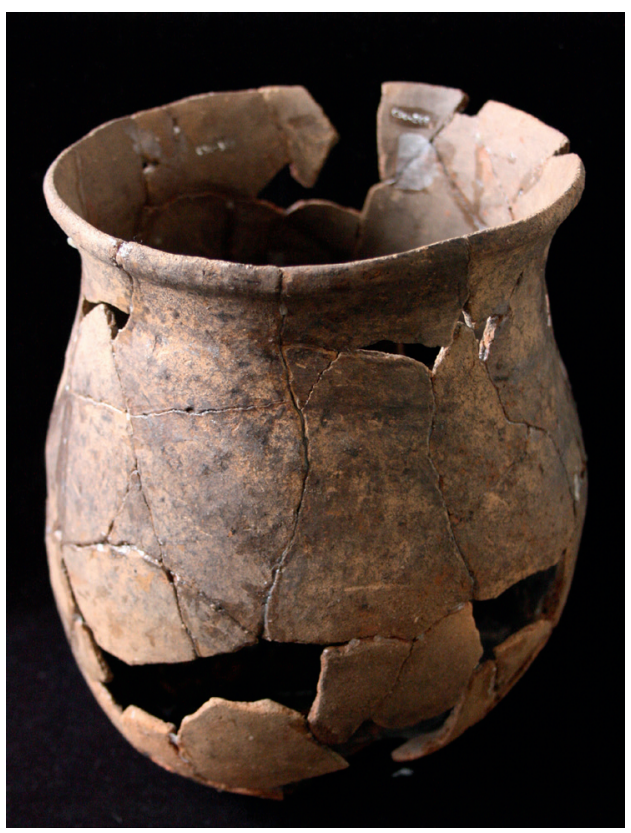

Fig. 3. Cerâmica da tradição Itararé-Taquara encontrada na casa subterrânea de Itapeva (SP). Pesquisa de Kamase (2004, 2005). Remontagem: Dária Elânia Fernandes Barreto. Foto: Marianne Sallum. 
apresentou uma área circular deprimida, com aproximadamente $6 \mathrm{~m}$ de diâmetro e $50 \mathrm{~cm}$ de profundidade no ponto central, vestígios líticos lascados e muitos líticos com marcas de ação térmica, estrutura de combustão e buraco de esteio (fig. 4). Das 4 datas obtidas, 2 são mais confiáveis em comparação com o quadro cronológico regional: $1270 \pm 100$ (fragmento lítico queimado) e $800 \pm 100$ anos BP por TL e LOE (Afonso e Morais 2005: 26-27).

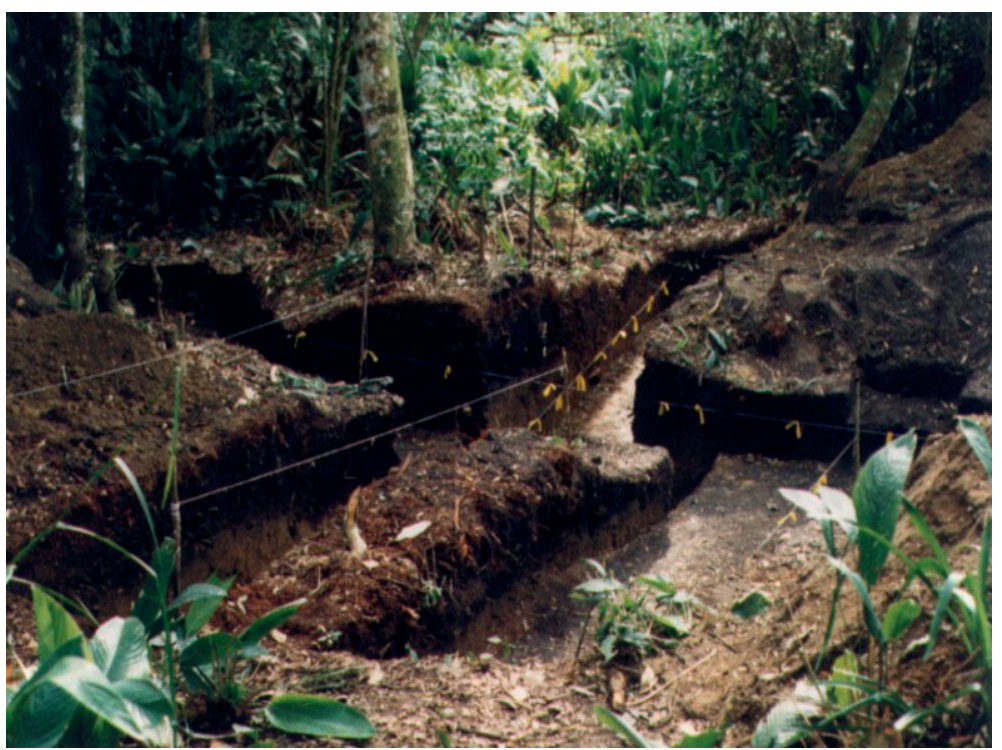

Fig. 4. Sítio Barra do Turvo - casa subterrânea (Município Barra do Turvo, SP). Foto: Marisa Coutinho Afonso.

Em São José dos Campos, a equipe de A Lasca Arqueologia localizou o sítio Carcará associado à tradição Itararé-Taquara pelas características do material cerâmico, particularidades dos artefatos líticos e presença de uma casa subterrânea (Lima et al. 2013; A Lasca Arqueologia 2016: 195 e 210). Lima et al. (2013) informam sobre a surpresa e o caráter especial do achado da casa subterrânea, uma depressão circular de $4 \mathrm{~m}$ de diâmetro com peças líticas e estruturas de lascamento; apontam também que este sítio comprova o avanço mais setentrional de populações construtoras de estruturas habitacionais subterrâneas no Vale do Paraíba do Sul, visto que antes era dado crédito às bacias do Rio Ribeira de Iguape e do Alto Paranapanema como os avanços máximos.

Duas amostras, de cerâmica e sedimento, foram usadas por datação por Luminescência Oticamente Estimulada (LOE) com os seguintes resultados: $960 \pm 130$ e $500 \pm 70$ anos, respectivamente (A Lasca 2016: 197). Também foram obtidas 2 datas radiocarbônicas para 2 estruturas de combustão que correspondem ao período de ocupação da tradição Itararé-Taquara: $760 \pm 30 \mathrm{AP}$, datação calibrada AD 1275 a 1290 e $810 \pm 30$ AP, datação calibrada AD 1225 a 1280 (A Lasca 2016: 201). O material cerâmico apresentou acabamento de superfície com enegrecimento ou brunidura, formas de vasilhames globulares e espessura de parede fina, indicando correlação à indústria cerâmica da Tradição Itararé-Taquara (A Lasca 2016: 217).

Sítios filiados às tradições Aratu e Uru

Na discussão sobre a tradição dos grupos Jê do Planalto, Pedro Ignacio Schmitz informou que a tradição Aratu ocuparia ao menos a Bahia, parte do Espírito Santo, Piauí, o centro de Goiás e o norte de São Paulo, com a observação 
de Ondemar Dias Júnior sobre o norte de São Paulo ter sido feito por correspondência e não por manuseio de material (Schmitz et al. 1980: 14). Nota-se que em 1980 , apesar das poucas pesquisas realizadas com sítios cerâmicos em São Paulo, já se mencionava a presença de sítios da tradição Aratu no norte do Estado.

Na região do rio Pardo (bacia do rio Grande), foi localizado o sítio Tamanduazinho, no Município de São Simão, datado de $990 \pm 70$ anos (TL) e com características não semelhantes à cerâmica da tradição Tupiguarani (Afonso 1987). Este sítio foi identificado durante a realização de pesquisas sistemáticas na área em projeto coordenado por Solange Bezerra Caldarelli e Walter Alves Neves e só houve a coleta de material para datação já que era o único sítio cerâmico identificado naquele Município. Caldarelli e Neves (1981: 35) já haviam apontado que "quanto aos horticultores, nitidamente representados na área por duas ocupações distintas, uma Gê e uma Tupi-Guarani, a problemática que se nos apresenta atualmente é de ordem cronológica". Os autores referem-se aos documentos históricos que mencionam apenas populações indígenas do grupo linguístico Jê, como os Caiapó, concluindo que haveria ocupação Jê no vale do rio Pardo (afluente do rio Grande).

O estudo do sítio Água Branca (localizado no Município de Casa Branca no norte de São Paulo e próximo ao rio Pardo) apresentou um grande interesse porque sua cerâmica possui características das chamadas Tradições AratuSapucaí (cariapé, formas duplas, apêndices, brunidura), Tupiguarani (caco moído, ombros indicando vasos de formas complexas) e Uru (cariapé, bases planas com ângulos de $90^{\circ}$ ). A planta do sítio, com a indicação das áreas de maior concentração de cerâmica, revelou uma estrutura elíptica de 200 metros por 140 metros, tendo sido coletadas quase 1500 peças com estação total (Afonso e Moraes 2005/2006). As características da cerâmica, a datação recente (205 \pm 20 anos BP por termoluminescência para um fragmento cerâmico), a morfologia aproximadamente circular da aldeia e os dados levantados pela pesquisa etnohistórica indicam que o grupo que ocupou o sítio Água Branca está associado à ocupação Jê da região. Este sítio permite uma maior reflexão sobre as influências dos grupos do Brasil Central no território paulista, além de questões sobre deslocamentos geográficos e interação cultural.

As cerâmicas dos sítios Lagoa Preta II (localizado no Município de Serra Azul) e Água Branca mostram várias características comuns como a presença de cariapé, bases planas, ausência de decoração e bom tratamento de superfície (Afonso e Moraes 2005/2006). Essas semelhanças, aliadas às datas relativamente próximas, indicam que ambos os sítios podem ter feito parte de um mesmo sistema regional de povoamento (no sentido proposto por Morais 1999/2000). A análise do sítio Água Branca mostrou que está associado a uma ocupação ceramista que, até aquele momento, não havia sido reconhecida na região.

Outros sítios, relacionados à tradição Aratu, foram também localizados em São Paulo, na bacia do rio Grande: sítio Maranata, localizado no município de Olímpia (Maranca et al. 1994), sítio Água Limpa, no município de Monte Alto (Alves et al. 1995; Alves et al. 1996, Fernandes 2001) e o sítio Água Vermelha II, no município de Ouroeste (Robrahn-González et al. 1998).

O sítio Maranata foi filiado à tradição Aratu-Sapucaí com base na reconstituição das formas dos vasilhames (Maranca et al. 1994: 226) e foi o primeiro sítio desta tradição localizado no Estado de São Paulo.

O sítio Água Limpa é um sítio a céu aberto, datado de 1524 anos AP (TL), que apresenta estruturas de combustão, sepultamentos primários de indivíduos adultos, sepultamentos secundários, restos alimentares (Alves et al. 1996). A análise dos vestígios cerâmicos levou a sua filiação à tradição Aratu-Sapucaí (Fernandes 2001). Apresenta outras datas como $720 \pm 70$ anos AP para uma borda ondulada e $456 \pm 50$ anos AP.

Os sítios Água Vermelha 1 e 2 foram localizados em Ouroeste (SP), sendo que o Água Vermelha 1 apresenta cariapé aproximando-o da tradição Uru. O sítio Água Vermelha 2 apresentou 2 datações: $1010 \pm 50$ anos BP e $700 \pm$ 70 anos BP.

O sítio Baixadão, localizado no município de Paulo de Faria (SP), também pode ser filiado à tradição Aratu-Sapucaí (Penin et al. 2005/2006). 
Moraes (2007) estudou a variabilidade artefatual em sítios arqueológicos associados à Tradição Tupiguarani no nordeste do Estado de São Paulo e notou que sítios Tupi como o Lambari II (Casa Branca, SP) e Cachoeira de Emas 2 (Pirassununga, SP) estão associados a contextos onde, a menos de $1 \mathrm{~km}$, há ocupações ceramistas não-Tupi com características similares e datações tardias. Para a autora, a descoberta de sítios associados às Tradições Aratu e Uru no nordeste do Estado de São Paulo e as informações etnográficas que sugerem a dominação desse território por índios kaiapó nos séculos XVII-XVIII mostram que é necessário uma melhor avaliação da interação desses grupos e os grupos Tupi.

A Zanettini Arqueologia (2008) realizou pesquisas no norte/nordeste do estado de São Paulo onde foram localizados os sítios Olímpia I, II, III, IV, V e VI, identificando a proximidade espacial dos sítios com diferentes tradições culturais (Tupiguarani, Aratu/Sapucaí e Uru).

Moraes-Wichers et al. (2008) apresentaram dados a respeito de três estudos distintos realizados no estado de São Paulo, envolvendo sítios com cerâmicas relacionadas às tradições Tupiguarani e Aratu/Uru, datados entre 490 e 205 anos AP, focando na variabilidade dos conjuntos cerâmicos que apontam nitidamente para o intercâmbio de informações, objetos e/ ou pessoas nos assentamentos em análise. $\mathrm{O}$ primeiro estudo de caso referiu-se ao médio vale do rio Pardo, onde foram localizados os sítios arqueológicos Lambari II (Afonso 2005; Moraes 2007), de tradição Tupiguarani, e Água Branca (Afonso e Moraes 2005/2006), com componentes das tradições Aratu e Uru, distantes 1 $\mathrm{km}$ entre si, no município de Casa Branca. O segundo estudo foi desenvolvido na área de Cachoeira de Emas (rio Mogi-Guaçu), município de Pirassununga (Zanettini Arqueologia 2006; Moraes 2007) onde foram localizados o sítio Cachoeira de Emas 1 apresentando material com características Aratu/Uru, semelhante ao material resgatado no sítio Água Branca, e o sítio Cachoeira de Emas 2 (tradição Tupiguarani) nas imediações do sítio Cachoeira de Emas 1. O terceiro caso refere-se à Olímpia, região noroeste do Estado de São Paulo, com 7 sítios arqueo- lógicos relacionados às ocupações ceramistas e localizados durante o licenciamento ambiental pela Zanettini Arqueologia, entre eles o sítio Olímpia IV, associado à tradição Tupiguarani, e Olímpia VII, com características das tradições Aratu/Uru (semelhante à situação dos sítios Água Branca e Cachoeira de Emas 1), guardando igualmente relativa proximidade (Zanettini Arqueologia 2008).

Faccio et al. (2014) apresentam um mapa do estado de São Paulo com a localização de 26 sítios arqueológicos filiados à tradição Aratu no norte do Estado de São Paulo: Bambu, Abelha, Dourado, Ararinha, Da Mata, Ferreiras, Oficina, Turvo I, Turvo II, Turvo III, Turvo IV, Turvo V-A, Turvo V-B, Barra de Ouro, Santa Filomena, Menino Jesus, Rosário G2, Nova Índia, Cervo, Santo Ant. do Lageado, Guaíra, Bela Vista do Jacaré, Balsamina, Água Azul, Santana do Figueirão e Capão Escuro. Segundo os autores, os sítios da região do rio Turvo estão localizados em áreas de colinas ou chapadas, próximos a ribeirões ou córregos de água perene e rios na base. Umizi (2014: 63-64) realizou datações por termoluminescência em material cerâmico dos sítios Turvo III e Turvo V obtendo as seguintes idades médias: 1736 anos AP e 423 anos AP, respectivamente.

\section{Macro-Jê na Bacia do rio Paraíba do Sul}

As pesquisas realizadas na bacia do rio Paraíba do Sul, no Estado de São Paulo, têm apresentado características particulares. O sítio Caçapava I foi o primeiro a ser identificado nesta bacia e segundo Caldarelli (1999: 356), "o único sítio indígena localizado, no município de Caçapava, pertence à tradição cerâmica Aratu, variedade Sapucaí, apresentando mais de trinta sepultamentos em urnas funerárias não decoradas. Objeto de resgate em 1991, foi o primeiro sítio desta tradição escavado exaustivamente no estado de São Paulo". Gomes (2003a, b) analisou a cerâmica do sítio Caçapava I, confirmando a associação da indústria à tradição Aratu. Lopes (2014: 4676) apresentou um amplo quadro da ocupação pré-colonial no vale do Paraíba paulista, no leste do Estado de São Paulo; o autor, com base na 
leitura de fontes, observou que as populações Tupi e Jê, a partir de suas diferentes identidades étnicas, compuseram na região um mosaico cultural, com as relações se estabelecendo de forma dinâmica, ora através de conflitos, ora por meio de conciliações (Lopes 2014: 194).

Caldarelli (2011) e Morais (2011b) fizeram apresentações sobre "A ocupação Macro-Jê pré-colonial do vale do Paraíba paulista: o que evidenciam as pesquisas arqueológicas da primeira década do século XXI" na mesa redonda "Arqueologia do Sudeste: balanço geral, temas pertinentes" no Encontro de Arqueologia, Patrimônio e Turismo (EAPT) ${ }^{2}$. Caldarelli (2011) apontou que pesquisas realizadas pela Scientia no médio e baixo vales do rio Paraíba do Sul em São Paulo indicaram que a ocupação Macro-Jê antecedeu bastante a ocupação Tupi, testemunhadas por dois sítios culturalmente distintos: Caçapava 1 e Topo de Guararema. Para a autora, o sítio Caçapava 1 (Município de Caçapava) filia-se à tradição Aratu, com grandes urnas funerárias piriformes, mas com características diferentes dos outros sítios paulistas atribuídos à mesma tradição no norte e nordeste do Estado que estão mais próximos da tradição Aratu/Sapucaí. O sítio Topo de Guararema (município de Guararema) apresenta características semelhantes às da tradição Itararé, mas Caldarelli (2011) não adota este nome para o Vale do Paraíba porque os dados etnohistóricos não apontam a presença de índios Kaingang, prefere usar "Cultura Guaianá” já que a cerâmica analisada é semelhante à registrada entre os grupos Jê históricos, em contraposição à tradição Itararé.

Morais (2011b) discutiu o sítio Ribeiro, localizado no Município de Paraibuna (SP) durante as investigações arqueológicas relacionadas com o licenciamento ambiental do Gasoduto Caraguatatuba-Taubaté. O sítio apresenta um extenso núcleo de solo antropogênico circular com 12 m de diâmetro e 15.000 fragmentos

$2 \mathrm{O}$ Encontro de Arqueologia, Patrimônio e Turismo (EAPT) foi realizado em Rio Claro, SP, de 27 a 29 de junho de 2011, com a comissão organizadora composta por Astolfo Gomes de Melo Araujo (MAE/USP), Bernadete Castro de Oliveira (UNESP) e Antonio Carlos Sarti (EACH/USP). cerâmicos; com a análise de 460 fragmentos de bordas foram identificadas morfologias associadas tanto à tradição Aratu quanto à tradição Taquara-Itararé (Guaianá?) da bacia do Paraíba do Sul, trecho paulista ${ }^{3}$.

A equipe da Origem Arqueologia, durante as obras de duplicação da Rodovia dos Tamoios, localizou no Município de Paraibuna um sítio filiado à tradição Aratu, pela tipologia do material e padrão de ocupação do sítio (Bornal 2013).

No litoral, o sítio Viana foi identificado por Dorath Pinto Uchoa e Caio Del Rio Garcia (Instituto de Pré-História/USP) na década de 1970 ao norte de Ilhabela e o material coletado foi analisado por Bendazzoli (2014). Além dos 1770 fragmentos cerâmicos, 328 líticos e 15 exemplares malacológicos, há uma urna funerária com formato piriforme e remanescentes esqueletais. Segundo Bendazzoli (2014), a reconstituição morfológica dos vasilhames do sítio Viana evidenciou a presença de potes e tigelas utilitárias de pequeno porte, associados à armazenagem de líquidos e de preparo e consumo de alimentos. Após a análise das características tecnológicas, morfológicas e estilísticas das cerâmicas dos sítios Viana e Barra Velha 3 e das cerâmicas localizadas nos topos nos sambaquis, Bendazolli (2014: 286-287) conclui que são filiados à tradição Aratu, descartando a interpretação de Cali sobre a presença de cerâmica da tradição Itararé em Ilhabela.

A presença de cerâmica nos sambaquis de Ilhabela é interessante porque só havia um relato anterior para o litoral de São Paulo no sambaqui Maratuá (Guarujá, SP) com raros fragmentos de cerâmica de origem indígena na camada superior (Emperaire e Laming 1956: 47), embora a cerâmica esteja presente nos sambaquis do norte, nordeste e sul. Para Bendazzoli (2014), a chegada dos grupos ceramistas Jê no litoral, vindos do vale do Paraíba do Sul, levou à ocupação

3 As análises e observações da cerâmica do sítio Ribeiro foram feitas por Lorena Luana Wanessa Gomes Garcia (Morais 2011). A comunicação apresentada no Simpósio teve como autores: José Luiz de Morais, Silvia Cristina Piedade, João Carlos Alves, Carlos Alberto Alves, Dária Elânia Fernandes Barreto e José Paulo Jacob, com a colaboração de Lorena Luana Wanessa Gomes Garcia. 
de áreas dos sambaquieiros, inclusive chegando a ilhas mais afastadas do continente. Bendazzoli (2014: 289-291) obteve datações por termoluminescência dos sítios onde foram evidenciados materiais cerâmicos, sejam sambaquis, aldeias ou abrigos mostrando que a ocupação ceramista ocorreu pelo menos desde $480 \pm 85$ AP (topo do sambaqui Abrigo das Furnas, no norte da Ilha de São Sebastião) até $190 \pm 25$ AP (topo do sambaqui do Paredão, Ilha dos Pescadores, Arquipélago da Vitória), configurando uma ocupação Jê de pelo menos 300 anos. É importante destacar as datas obtidas para as aldeias Jê: sítio Viana $(380 \pm 45$ AP) e Barra Velha 3 ( $290 \pm 30$ AP), indicando que o estabelecimento em aldeias ocorreu no mesmo período da ocupação dos topos de sambaquis e abrigos.

\section{Considerações finais}

A ocupação Jê no Estado de São Paulo está sendo identificada em várias partes do seu território de norte a sul, incluindo o litoral: na região sul (bacias dos rios Paranapanema e Ribeira de Iguape), na área central (bacia do rio Tietê, inclusive na cidade de São Paulo), no noroeste, no norte/nordeste, na bacia do rio Grande, bacia do rio Paraíba do Sul e no litoral norte, em ilhas e no topo de sambaquis.

As interações dos grupos Tupi e Jê no Estado de São Paulo estão sendo melhor identificadas quantos às fronteiras culturais e cronologia pelo maior número de sítios localizados e estudados. $\mathrm{O}$ entendimento das ocupações no Estado é fundamental para a compreensão das rotas de dispersão dos grupos Jê meridionais, dos Jê do Planalto Central, dos Tupi do norte e dos Guarani do sul; portanto a pesquisa arqueológica do território paulista pode contribuir para a melhor compreensão do contexto espacial e temporal dos grupos ceramistas de várias regiões brasileiras.

A continuidade das pesquisas sobre a ocupação Jê no estado de São Paulo pode ser realizada de diversas maneiras: 1) com novas pesquisas, estudo e divulgação de dados; 2) com a organização dos dados e melhor entendimento do conhecimento já produzido, como o trabalho de doutorado de Glauco Constantino Perez e a identificação dos sítios cerâmicos na região entre os rios Tietê e Paranapanema (Perez et al. 2015); 3) melhor entrosamento dos dados históricos, etnohistóricos e arqueológicos como os trabalhos de Robson Rodrigues com os Kaingang da região oeste de São Paulo (Rodrigues 2007) e Renan Pezzi Rasteiro sobre os Jê na região norte de São Paulo (Rasteiro 2015); 4) mais datações para melhorar o quadro cronológico da ocupação.

\section{Agradecimentos}

Agradeço ao MAE/USP pelo apoio institucional e ao CNPq pela bolsa de produtividade. A José Luiz de Morais, Robson A. Rodrigues, Camila de Azevedo Moraes Wichers, Renan Pezzi Rasteiro, Marianne Sallum, Marcel Lopes, Astolfo Gomes de Melo Araujo e Saul Milder (in memoriam) pelas discussões sobre os sítios cerâmicos de São Paulo. Ao José Luiz de Morais pela divulgação das comunicações que ele e Solange Bezerra Caldarelli apresentaram no Encontro de Arqueologia, Patrimônio e Turismo (EAPT) realizado em Rio Claro, SP, de 27 a 29 de junho de 2011.

AFONSO, M.C. Jê Archaeology in São Paulo State. R. Museu Arq. Etn., 27: 30-43, 2016.

\begin{abstract}
This paper presents a synthesis of Jê occupation in São Paulo State and discusses the archaeological, geographical and chronological contexts, focusing on sites associated to Jê groups and the Itararé-Taquara, Aratu-Sapucaí e Uru traditions.
\end{abstract}

Keywords: Jê Archaeology; Ceramic groups; Itararé tradition; Aratu tradition; São Paulo; Cultural frontiers. 


\section{Referências bibliográficas}

Afonso, M.C. 1987. Ocupação pré-histórica na região de Serra Azul e São Simão, São Paulo: um estudo geoarqueológico. Dissertação de mestrado. Universidade de São Paulo, São Paulo.

Afonso, M.C. 2005. Um Olhar para a Arqueologia Pré-Histórica do Estado de São Paulo. Tese de Livre Docência. Universidade de São Paulo, São Paulo.

Afonso, M.C. 2008/2009. Um painel da arqueologia pré-histórica no Estado de São Paulo: os sítios cerâmicos. Especiaria 11, 12(20, 21): 127-155.

Afonso, M. C. 2014. Arqueologia Jê no Estado de São Paulo. In: Simpósio Arqueologia dos Povos Jê no Sul e Sudeste do Brasil, Caderno de Resumos. São Paulo: Museu de Arqueologia e Etnologia/USP, 16.

Afonso, M.C.; Moraes, C.A. 2005/2006. O Sítio Água Branca: Interações Culturais dos Grupos Ceramistas no Norte do Estado de São Paulo. Revista do Museu de Arqueologia e Etnologia 15/16: 59-71.

Afonso, M.C.: Morais, J.L. 2005. Uma casa subterrânea no sul de São Paulo (bacia do rio Ribeira de Iguape. In: Milder, S. (Org.) Anais do I Colóquio sobre Sítios Construidos: Casas Subterrâneas. Pallotti, Santa Maria, 11-35.

Afonso, M.C.; Sallum, M.; Lopes, M. 2009. Ocupações ceramistas Tupi e Gê em São Paulo: espacialização e cronologia. In: XV Congresso Sociedade de Arqueologia Brasileira. Trabalhos completos. Belém: Sociedade de Arqueologia Brasileira (SAB), 8-15.

A Lasca Arqueologia. 2016. Resgate do sítio arqueológico Carcará - Fases 2 e 3. Monitoramento na área do sítio arqueológico Carcará. Resgate científico do patrimônio cultural arqueológico no Loteamento
Alphaville - São José dos Campos/SP. Relatório final de laboratório. Tomo II. A Lasca Arqueologia, São Paulo.

Alves, M.A.; Calleffo, M.E.V. 1996. Sítio de Água Limpa, Monte Alto, São Paulo - estruturas de combustão, restos alimentares e padrões de subsistência. Revista do Museu de Arqueologia e Etnologia 6: 123-149.

Alves, M.A.; Cheuiche-Machado, L. 1995. Estruturas Arqueológicas e Padrões de Sepultamento do Sítio de Água Limpa, Município de Monte Alto, São Paulo. Anais. VIII Reunião Científica da Sociedade de Arqueologia Brasileira, Porto Alegre, PUCRS, 1 (2): 295-310.

Amenomori, S.N. 1999. Potencial analítico de sedimentos e solos aplicado à arqueologia. Dissertação de mestrado. Universidade de São Paulo, São Paulo.

Araujo, A.G.M. 1995. Levantamento Arqueológico da área Alto Taquari, Estado de São Paulo, com ênfase na Abordagem dos Sítios Líticos. Dissertação de mestrado. Universidade de São Paulo, São Paulo.

Araujo, A.G.M. 2001. Teoria e Método em Arqueologia Regional: um estudo de caso no Alto Paranapanema, Estado de São Paulo. Tese de doutorado. Universidade de São Paulo, São Paulo.

Araujo, A.G.M. 2007. A tradição cerâmica Itararé-Taquara: características, área de ocorrência e algumas hipóteses sobre a expansão dos grupos Jê no sudeste do Brasil. Revista de Arqueologia 20: 09-38.

Araujo, A.G.M. 2016. Explorando a espacialidade de um sítio Itararé-Taquara: estudo de caso do sítio Areia Branca 5, sudeste do Estado de São Paulo. Revista do Museu de Arqueologia e Etnologia 27: 55-82. 
Bendazzoli, C. 2014. O panorama da ocupação sambaquieira no Arquipélago de Ilhabela, SP. Tese de doutorado. Universidade de São Paulo, São Paulo.

Bornal, V. (2013) Estrada com história. Obras em rodovia em São Paulo revelam achados arqueológicos. Ciência Hoje para crianças, $12 / 8 / 2013$

Caldarelli, S.B. 1999. Levantamento arqueológico em planejamento ambiental. Revista do Museu de Arqueologia e Etnologia, Suplemento 3: 347-369.

Caldarelli, S.B. 2011. A ocupação macro-jê précolonial do vale do Paraíba paulista: o que evidenciam as pesquisas arqueológicas da primeira década do século XXI - I. Resumo. Encontro de Arqueologia, Patrimônio e Turismo (EAPT), Rio Claro.

Caldarelli, S.B. 2015. Arqueologia preventiva: uma disciplina na confluência da arqueologia pública e da avaliação ambiental. Habitus 13 (1): 5-30.

Caldarelli, S.B.; Neves, W.A. 1981. Programa de Pesquisas Arqueológicas no Vale do Rio Pardo. Revista de Pré-História 3: 13-49.

Cali, P. 2005. Políticas municipais de gestão do patrimônio arqueológico. Tese de doutorado. Universidade de São Paulo, São Paulo.

DeBlasis, P.A.D. 2000. Resgate Arqueológico no Traçado do Gasoduto Bolívia-Brasil (GASBOL) no Estado de São Paulo: Trechos IX e $X$ (de Paulínea à fronteira com o Paraná). Relatório Final, São Paulo, Museu de Arqueologia e Etnologia, Universidade de São Paulo.

Emperaire, J., Laming, A. 1956. Les sambaquis de la cote méridionale du Brésil. Journal de la Société des Américanistes 45 (1): 5-164.

Faccio, N.B.; Barrocá, D. 2014. Sítio arqueológico Jê no noroeste do estado de São Paulo: o sítio Kandiri. Caderno de Resumos. Simpósio:
Arqueologia dos povos Jê no sul e sudeste do Brasil. Museu de Arqueologia e Etnologia, Universidade de São Paulo, 38.

Faccio, N.B.; Costa, H.A.V.; Luz, J.A.R.; Barrocá, D.; Matheus, E.P. 2014. Vasilhas duplas Aratu (Macro-Jê) em sítio tupi-guarani: evidência de contato? Revista Ágora 20: 6-23.

Fernandes, S.C.G. 2001. Estudo tecnotipológico da cultura material das populações pré-históricas do Vale do Rio Turvo, Monte Alto, São Paulo e a Tradição Aratu-Sapucaí. Dissertação de mestrado. Universidade de São Paulo, São Paulo.

Gomes, D.M.C. 2003a. A cerâmica indígena do sítio Caçapava I. In: Caldarelli, S.B. (Coord.). Arqueologia do Vale do Paraíba Paulista. SP-070 Rodovia Carvalho Pinto. Dersa Desenvolvimento Rodoviário S.A., 214-220.

Gomes, D.M.C. 2003b. A distribuição da Tradição Aratu no território brasileiro. In: Caldarelli S.B. (Coord.). Arqueologia do Vale do Paraíba Paulista. SP-070 Rodovia Carvalho Pinto. Dersa Desenvolvimento Rodoviário S.A., 221-224.

Kamase, L. 2004. Casas subterrâneas e feições doliniformes: um estudo de caso no Alto Paranapanema (SP). Dissertação de mestrado, São Paulo: Universidade de São Paulo.

Kamase, L. 2005. A pesquisa arqueológica no Alto Paranapanema (SP): Casas subterrâneas e feições doliniformes. In. Milder, S. (org.) Anais do I Colóquio sobre Sítios Construídos: Casas Subterrâneas. Santa Maria, Pallotti: 37-56.

Lima, L.F.E.; Juliani, L.J.O.; Belém, F.R.; Lôbo, J. 2013. A presença de uma casa subterrânea no vale do Paraíba do Sul, Estado de São Paulo, Brasil. Caderno de Resumos. III Semana Internacional de Arqueologia "André Penin". Museu de Arqueologia e Etnologia, Universidade de São Paulo, 46. 
Lopes, M. 2014. Ocupação tupinambá no vale do Paraíba paulista: vista a partir da análise do sítio arqueológico Santa Marina. Dissertação de mestrado. Universidade de São Paulo, São Paulo.

Maranca, S. 1968/1969. Nota prévia sobre o sítio José Fernandes (SP-IP 12). Revista do Museu Paulista 18: 105-118.

Maranca, S. 1969. Dados Preliminares sobre a arqueologia do Estado de São Paulo. In: Arqueologia Brasileira em 1968. Publicações Avulsas, Museu Paraense Emilio Goeldi, Belém 12: 133-139.

Maranca, S.; Silva, A.L.M.; Scabello, A.M.P. 1994. Projeto Oeste Paulista de arqueologia do Baixo e Médio Vale do rio Tietê: síntese dos trabalhos realizados. Revista de Museu de Arqueologia e Etnologia 4: 223-226.

Milder, S. (org.) 2005. Anais do I Colóquio sobre Sítios Construidos - Casas Subterrâneas. Santa Maria: Pallotti.

Miller Jr., T.O. 1972. Arqueologia da Região Central do Estado de São Paulo. Dédalo 8 (16): 13-118.

Moraes, C.A. 2007. Arqueologia Tupi no Nordeste de São Paulo: um estudo de variabilidade artefatual. Dissertação de mestrado. São Paulo, Universidade de São Paulo.

Moraes Wichers, C.A.; Zanettini, P.E.; Afonso, M.C. 2008. Tupis e Tapuias: interação cultural em três contextos arqueológicos do Estado de São Paulo. In: $2^{\circ}$ Simpósio de Arqueologia e Patrimônio de Minas Gerais/ $2^{\circ}$ Simpósio Regional de Arqueologia e Patrimônio da Zona da Mata Mineira, Carangola. Caderno de Resumos: 12.

Morais, J.L. 1999. Perspectivas geoambientais da arqueologia do Paranapanema Paulista. Tese de Livre Docência. Universidade de São Paulo, São Paulo.
Morais, J. L. 1999/2000. Arqueologia da região Sudeste. Revista da USP 44: 194-217.

Morais, J.L. 2011a. Perspectivas geoambientais da Arqueologia do Paranapanema paulista. Habilis, Erechim.

Morais, J.L. 2011b. A ocupação macro-jê précolonial do vale do Paraíba paulista: o que evidenciam as pesquisas arqueológicas da primeira década do século XXI - II. Resumo. Encontro de Arqueologia, Patrimônio e Turismo (EAPT), Rio Claro.

Pallestrini, L. 1968/69. O sítio arqueológico Jango Luís. Revista do Museu Paulista 18: 26-56.

Pallestrini, L. 1974. Sítio arqueológico Alves. Revista do Museu Paulista, Nova Série XXI: 47-96.

Pallestrini, L. 1983. "Superfícies amplas” em arqueologia pré-histórica no Brasil. Revista de Arqueologia 1 (1): 7-18.

Penin, A.; DeBlasis, P. 2005/2006. Sítio Baixadão: um novo sítio Aratu no norte paulista. Revista do Museu de Arqueologia e Etnologia 15-16: 449-453.

Perez, G.C.; Afonso, M.C. 2015. Os ceramistas na paisagem paulista: uma proposta metodológica. Revista de Arqueologia Pública 9: 13-21.

Prous, A. 1979. Première information sur les maisons souterraines de l'État de São Paulo, Brésil. Revista de Pré-História 1(1): $127-145$.

Rasteiro, R.P. 2015. Arqueologia dos Jê da Bacia do Rio Grande: história indígena no Norte de São Paulo e no Triângulo Mineiro. Dissertação de mestrado. Universidade de São Paulo, São Paulo.

Robrahn, E.M. 1989. A Ocupação Pré-Colonial do Vale do Ribeira de Iguape, SP: Os Grupos 
Ceramistas do Médio Curso. Dissertação de mestrado. Universidade de São Paulo, São Paulo.

Robrahn-González, E. M. 2000. São Paulo, Terra de Fronteiras: a ocupação de grupos ceramistas pré-coloniais. In: Anais do IX Congresso da Sociedade de Arqueologia Brasileira, 1997, Rio de Janeiro (Cd-Rom).

Robrahn-González, E.M. 2005. Sociedade e Arqueologia. Tese de Livre Docência. Universidade de São Paulo, São Paulo.

Robrahn-González, E.M.; Afonso, M.C.; DeBlasis, P.A.D.; Figuti, L.; Neves, E.G.; Eggers, S. 1998. Água Vermelha: pesquisa arqueológica de salvamento. São Paulo: Museu de Arqueologia e Etnologia - Universidade de São Paulo, Contrato UPS/CESP, 1998.

Rodrigues, R.A. 2007. Os caçadores-ceramistas do sertão paulista: um estudo etnoarqueológico da ocupação Kaingang no vale do rio Feio/ Aguapeí. Tese de doutorado. Universidade de São Paulo, São Paulo.

Schmitz, P.I.; Barbosa, A.S.; Ribeiro, M.B. (Eds.) 1980. Os Cultivadores do Planalto e do Litoral. Temas de Arqueologia Brasileira em 1980, 5, Instituto Goiano de Pré-História e Antropologia, Universidade Católica de Goiás e Instituto Anchietano de Pesquisas, Universidade do Vale do Rio dos Sinos.

Souza, J.G.; Merencio, F.T. 2013. A diversidade dos sítios arqueológicos Jê do Sul no Estado do Paraná. Cadernos do LEPAARQ. Textos de Antropologia, Arqueologia e Patrimônio X (20): 93-130.

Umiji, R.M. 2014. Datação de Cerâmicas Arqueológicas do Noroeste Paulista pelo Método da Termoluminescência. Dissertação de Mestrado. Faculdade de Engenharia, UNESP Campus de Ilha Solteira.

Zanettini Arqueologia. 2006. Programa de Resgate Arqueológico - Empreendimento de Ponte de Concreto sobre o rio Mogi-Guaçu-Cachoeira de Emas, Município de Pirassununga, São Paulo. Relatório final.

Zanettini Arqueologia. 2008. Programa de Resgate e Monitoramento Arqueológico - Usina Guarani S/A - Açúcar e Álcool (Usina Cruz Alta Unidade III), Município de Olimpia, Estado de São Paulo. Relatório Final.

Zanettini Arqueologia. 2010. Mosaico paulista: guia do patrimônio arqueológico do estado de São Paulo. Zanettini Arqueologia, São Paulo. 